\title{
Role of Toll-like receptors in the development of allergic inflammation in asthma
}

\author{
Dominika Oleś, Aleksandra Szczepankiewicz
}

\author{
Laboratory of Molecular and Cell Biology, Department of Paediatric Pulmonology, Allergy and Clinical Immunology, \\ Poznan University of Medical Sciences, Poland \\ Head: Aleksandra Szczepankiewicz MD, PhD
}

Postep Derm Alergol 2012; XXIX, 4: 275-278

DOI: 10.5114/pdia.2012.30467

\begin{abstract}
Toll-like receptors (TLR) are a family of receptors that play an important role in innate immune response. Their presence has been confirmed in macrophages, dendritic cells, neutrophils and mast cells. Toll-like receptors receptors recognize microbial products and their activation triggers the innate immune response mechanism. They can also participate indirectly in the adaptive immune response. Allergic asthma is a chronic inflammatory disease with characteristic clinical symptoms including airway hypersensitivity, airway obstruction and wheezing. Airway inflammation is related to eosinophilia, elevated levels of inflammatory mediators and excessive mucus secretion. In animal models it has been shown that Toll-like receptors, because of their role in immunological processes, may be an important therapeutic target in asthma.
\end{abstract}

Key words: Toll-like receptors, allergic asthma, recombinant vaccine.

\section{Introduction}

Toll receptors were first discovered in Drosophila where they are involved in the defense mechanisms [1]. Receptors similar to Toll have been also identified in mammals and they were named Toll-like receptors (TLR). These receptors belong to transmembrane receptors and consist of three domains: extracellular, transmembrane and cytoplasmatic. The domains are composed of glycoproteins with molecular weight of 90-115 kDa with specific characteristics: extracellular domain contains leucine-rich repeats - LRR, cytoplasmic domain is similar to interleukin 1 receptor TIR (Toll-IL-1 receptor), with intracellular C-terminal end rich in cysteine residues responsible for the regulation of signal transduction (Figure 1) [2, 3].

Toll-like receptors are present in macrophages, dendritic cells, B cells, mast cells, eosinophils, neutrophils, epithelial cells, endothelial cells, cardiomyocytes and adipocytes [4]. Toll-like receptors belong to the PRR receptors (pattern recognition receptors) and play a role in innate immune response, and indirectly in adaptive immune response [5]. Medzhitov et al. showed that Toll receptors play a role in the induction of expression of cytokines such as interleukin-1, 6, 8 (IL-1, IL-6, IL-8) and activation of nuclear factor $\kappa \mathrm{B}(\mathrm{NF}-\kappa \mathrm{B})$ in the human immune system. This discovery proves that the TLR receptors also play a role in immune reactions in humans [6].

Toll-like receptors ligands are derived from microorganisms and include lipopolysaccharides (LPS), proteoglycans (PGN), heat shock proteins (HSP) and nucleic acids. These endogenous structures were termed pathogenassociated molecular patterns (PAMP). Binding the ligand to the TLR receptor triggers activation of specific immune response through increased synthesis of pro-inflammatory cytokines and antimicrobial factors as well as by stimulation of dendritic cells maturation. Moreover, TLRs can also activate antigen presenting cells (APCs) and induce the release of interleukins, chemokines, and nitric oxide. These processes lead to the activation of adaptive immune response [7].

To date, thirteen TLR receptors binding ligands from different microorganisms have been identified. Taking into account differences in the affinity for ligands, receptors were divided into five subfamilies: TLR2 subfamily, which consists of TLR1, TLR2, TLR6 that have high affinity for bacteria, TLR3 receptor that binds with RNA viruses, TLR4 that recognizes bacteria, heat shock proteins (HSP) and viruses, and TLR9 subfamily, which includes TLR7, TLR8, TLR9 and is associated with RNA and DNA viruses [3]. 


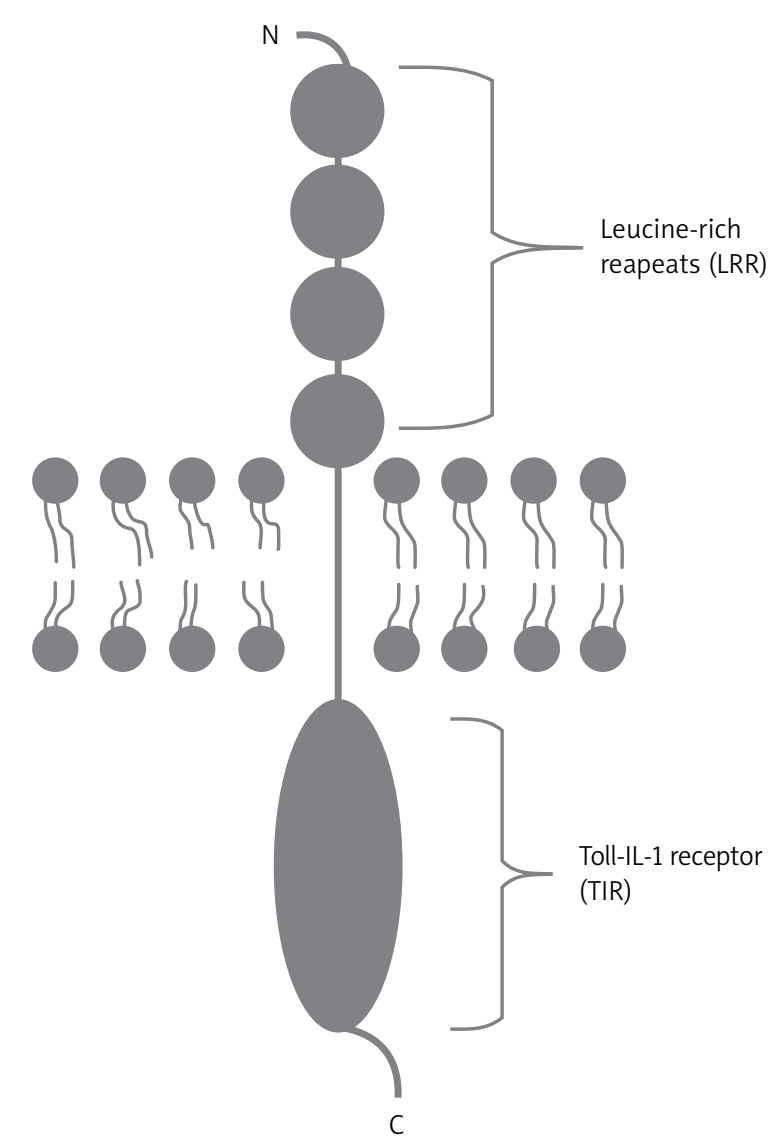

Figure 1. Toll-like receptor (modified by Akira, 2003 [3])

The important role of Toll-like receptors has been found in many diseases such as asthma, ischemic heart disease, coronary artery disease, non-specific inflammatory bowel disease, acute tubular necrosis, psoriasis, rheumatoid arthritis, tumor angiogenesis and transplant rejection processes. Taking into account the role of TLR receptors in the pathogenesis of many diseases, they are seen as potential therapeutic targets for the treatment [7, 8].

\section{Toll-like receptors and allergic asthma}

Allergic asthma is a chronic inflammatory disease with characteristic clinical symptoms including airway hypersensitivity, airway obstruction and wheezing [9]. Airway inflammation is related to eosinophilia, elevated levels of mediators of inflammation and excessive mucus secretion. An important role in the development of asthma was attributed to Th1 and Th2 cells. The Th1 population is responsible for the mechanism of cell response and Th1 cells' ability to secrete interleukin 2 (IL-2) and interferon $\gamma$ (INF- $\gamma$ ). Th2 cells are responsible for the humoral response and overproduction of antibodies IgE and activating $B$ cells in asthmatics. Th2 cells are the source of interleukins (IL-4, IL-5, IL-6, IL-10, IL-13) [10]. In asthmatic patients, the balance between Th1/Th2 cell populations is shifted towards Th2 cells. Overexpression of cytokines contributes to the influx of a variety of effector cells and their stimulation that lead to inflammation and airway hypersensitivity [11, 12].

The development of allergic diseases from early childhood to adolescence later in life led to the development of the hygiene hypothesis. Studies in the neonatal immune system have shown that children that had no contact with the pathogens are more prone to allergy in adult life. The fetal Th2 phenotype (allergic) tends to persist after birth and later in life. This results in increased immune response upon contact with allergens [13]. Frequent contact with microorganisms in childhood triggers switch to Th1 phenotype. A limited contact with microorganisms in childhood contributes to the development of allergic Th2 phenotype, therefore, infections acquired early in life may protect children from asthma. Gram negative bacteria, mycobacteria and many viruses induce strong Th1 cell response [14]. Because of the role of TLR receptors in the immune response, in both humoral and cellular potency, they can be a target in antiasthmatic therapy.

Sel et al. showed in an animal model that synthetic ligands (polycytidylic-polyinosinic acid (p[l:C]) and R-848) for TLR3 and TLR7 prevented the production of IgE and IgG1 antibodies. Therefore, systemic application of the synthetic ligands for TLR3 and TLR7 protects against the development of asthmatic symptoms and reduces the symptoms already present such as allergic airway inflammation and airway hyperresponsiveness [15].

Vultaggio et al. showed that 9-benzyl-2-butoxy8-hydroxy adenine, called SA-2, a ligand for TLR7, inhibits both Th17 and Th2 response [16]. TLR7 and TLR9 can protect from allergic diseases by stimulation of antigen presenting cells to secrete cytokines that favor Th1 responses. TLR7 is expressed in natural killer T cells (NKT) which are capable of secretion of interferon $\gamma$ that supports the development of Th1 response [17]. Moreover, it has been shown that adolescents with asthma have reduced TLR7 function that possibly increases their susceptibility to viruses causing respiratory diseases [18].

In the animal models of asthma Kline et al. demonstrated that TLR9 ligand (oligonucleotides containing unmethylated CpG sequences [CpG-ODNs]) can prevent ariway inflammation. Administration of oligonucleotides containing unmethylated CpG sequences (CPG-ODNs) prevents induction of Th2 cytokine production, airway eosinophilia, bronchial hyperreactivity and IgE production [19]. Moreover, Jain et al. showed that TLR 9 ligand - CpG oligodeoxynucleotides (CPG-ODNs) also prevents ariway remodeling in a murine model of chronic asthma. They sensitized mice to ovalbumin that susequently led to the development of airway remodeling (subepthelial colagen depositon, goblet cell hyperplasia). Meanwhile, mice that received $\mathrm{CpG}$ oligodeoxynucleotides had a significantly reduced risk of airway remodeling [20]. 
Studies on TLR6 indicated this receptor as a potential therapeutic target for asthma treatment. Moreira et al. demonstrated that TIr6 $\sigma^{--}$mice challenged with Aspergillus fumigatus and house dust mite allergens developed chronic asthma demonstrating a significantly lower level of IL-23 and IL-17 as compared to the wild type mice with induced asthma. Interleukin-23 produced by macrophages and dendritic cells influences differentiation of T cells towards Th17 subpopulation. Th17 cells produce IL-17 responsible for activation of neutrophils and to extracellular bacteria and fungi. Administration of exogenous IL23 to mice resulted in the restored production of IL17 and reduced hyperresponsiveness as well as other asthmatic symptoms as compared to the untreated asthmatic Tir6 ${ }^{-}$mice [22].

Taken together, all these results suggest that TLR receptors may play an important role in the antiasthmatic therapy.

\section{Recombinant vaccines}

Vaccines that have a structure similar to TLR receptor ligands may be also helpful in the therapy of patients with hypersensitivity. So far, there have been attempts to produce vaccines being ligands for TLR9. The study involved patients with allergic rhinitis sensitized to ambrosia, a potent allergen, who were tested with vaccine designed as TLR9 agonist [22]. The authors examined whether the major ragweed Amb A protein linked to CpG DNA ligand (conjugated referred to as Amb a I immunostimulatory DNA conjugate - AIC) is able to inhibit Th2 cytokine response, reducing the symptoms of allergic rhinitis during the pollen season. In studies by Creticos et al. a sample of patients suffering from allergic rhinitis were subjected to the second phase of the drug study [23]. Those patients received the AIC vaccine before the ragweed pollen season. A significant decrease in symptoms throughout the year was observed in treated patients, and also in subsequent years during the peak plant pollen season [22]. Preliminary results showed that the AIC vaccine blocked the Th2 response in peripheral blood [24, 25] and reduced eosinophilic rhinitis in the ragweed blooming season. Biopsies from the nose of treated patients showed an increased IFN level suggesting changes in the immune response, but did not show a reduced amount of IL-4 or eosinophils [26].

During in vitro studies, it was shown that binding of allergens with IgE on basophil causes their degranulation. Use of AIC vaccine significantly reduces histamine release from basophils following allergen challenge [23]. However, the AIC vaccine activates the Th1 phenotype of immune response that may contribute to the development of autoimmune diseases. For this reason, it should be carefully monitored.

Because of the role of TLR receptors in immunological processes as evidenced by the described results of stud- ies based on animal models analyzing these receptors, they are an important therapeutic target for asthma.

\section{Acknowledgments}

Authors wish to thank Berenika Kasprzak for help in the establishment of the manuscript.

\section{References}

1. Lemaitre B, Nicolas E, Michaut L, et al. The dorsoventral regulatory gene cassette spatzle/toll/cactus controls the potent antifungal response in Drosophila adults. Cell 1996; 86: 973-83.

2. Takeda K, Akira S. TLR signaling pathways. Semin Immunol 2004; 16: 3-9.

3. Akira S. Toll-like receptor signaling. J Biol Chem 2003; 278: 38105-8.

4. Tokarz-Deptuła B, Niedźwiedzka P, Deptuła W. Receptory Toll-podobne-nowe znaczniki w immunologii. Alergia Astma Immunologia 2006; 11: 23-8.

5. Yang RB, Mark MR, Gray A, et al. Toll-like receptor-2 mediates lipopolysaccharide-induced cellular signalling. Nature 1998; 17: 284-8.

6. Medzhitov R, Preston-Hurlburt P, Janeway CA. A human homologue of the Drosophila Toll protein signals activation of adaptive immunity. Nature 1997; 24: 388-94.

7. Majewska M, Szczepanik M. Rola receptorów Toll-podobnych (TLR) w odporności wrodzonej i nabytej oraz ich funkcja W regulacji odpowiedzi immunologicznej. Postępy Hig Med Dosw 2006; 60: 52-63.

8. Cristofaro P, Opal MS. Role of Toll-Like receptors in infections and immunity. Drugs 2006; 66: 15-29.

9. Heldal KK, Mads $\varnothing$ L, Huser PO, Eduard W. Exposure, sympto ms and airway inflammation among sewage workers. Ann Agric Environ Med 2010; 17: 263-8.

10. Bloomfield SF, Stanwell-Smith R, Crevel RW, Pickup J. Too clean, or not too clean: the hygiene hypothesis and home hygiene. Clin Exp Allergy 2006; 36: 402-25.

11. Lemieszek M, Chilosi M, Golec M, et al. Mouse model of hypersensitivity pneumonitis after inhalation exposure to different microbial antigens associated with organic dusts. Ann Agric Environ Med 2011; 18: 159-68.

12. Kasznia-Kocot J, Kowalska M, Górny RL, et al. Environmental risk factors for respiratory symptoms and childhood asthma. Ann Agric Environ Med 2010; 17: 221-9.

13. Martinez FD, Holt PG. Role of microbial burden in aetiology of allergy and asthma. Lancet 1999; 354: 12-5.

14. Strachan DP. Hay fever, hygiene and household size. Br Med J 1989; 299: 1259-60.

15. Sel S, Wegmann M, Sel S, et al. Immunomodulatory effects of viral TLR ligands on experimental asthma depend on the additive effects of IL-12 and IL-10. J Immunol 2007; 178: 7805-13.

16. Vultaggio A, Nencini F, Pratesi S, et al. The TLR7 ligand 9-benzyl-2-butoxy-8-hydroxy adenine inhibits IL-17 response by eliciting IL-10 and IL-10-inducing cytokines. I Immunol 2011; 15: 4707-15.

17. Matesic D, Lenert A, Lenert P. Modulating Toll-like receptor 7 and 9 responses as therapy for allergy and autoimmunity. Curr Allergy Asthma Rep 2012; 12: 8-17. 
18. Roponen M, Yerkovich ST, Hollams E, et al. Toll-like receptor 7 function is reduced in adolescents with asthma. Eur Respir J 2010; 35: 64-71.

19. Kline JN, Waldschmidt TJ, Businga TR, et al. Modulation of airway inflammation by $\mathrm{CpG}$ oligodeoxynucleotides in a murine model of asthma. J Immunol 1998; 160: 2555-9.

20. Jain VV, Kitagaki K, Businga T, et al. CpG-oligodeoxynucleotides inhibit airway remodeling in a murine model of chronic asthma. J Allergy Clin Immunol 2002; 110: 867-72.

21. Moreira AP, Cavassani KA, Ismailoglu UB, et al. The protective role of TLR6 in a mouse model of asthma is mediated by IL-23 and IL-17A. J Clin Invest 2011; 121: 4420-32.

22. Creticos PS, Schroeder JT, Hamilton RG, et al. Role of Toll-Like receptors in infections and immunity. Drugs 2006; 66: 15-29.

23. Creticos PS, Eiden JJ, Balcer SL, et al. Immunostimulatory oligonucleotides conjugated to Amb a 1: safety, skin test reactivity, and basophil histamine release. J Allergy Clin Immunol 2000; 105: S70

24. Marshall JD, Abtahi S, Eiden JJ, et al. Immunostimulatory sequence DNA linked to the Amb a 1 allergen promotes $T(H) 1$ cytokine expression while downregulating $T(H) 2$-cytokine expression in PBMCs from human patients with ragweed allergy. J Allergy Clin Immunol 2001; 108: 191-7.

25. Simons FE, Shikishima Y, Van Nest G, et al. Selective immune redirection in humans with ragweed allergy by injecting Amb a 1 linked to immunostimulatory DNA. J Allergy Clin Immunol 2004; 113: 1144-51.

26. Tighe H, Takabayashi K, Schwartz D, et al. Conjugation of Immunostimulatory DNA to the short ragweed allergen amb a 1 enhances its immunogenicity and reduces its allergenicity. J Allergy Clin Immunol 2000; 106: 124-34. 